\title{
Distribution pattern and habitat preference of barking deer (Muntiacus muntjac Zimmermann) in Nagarjun forest, Kathmandu
}

\author{
Ajaya Nagarkoti* and Tej Bahadur Thapa \\ Central Department of Zoology, Tribhuvan University, Kirtipur, Kathmandu, NEPAL \\ *For correspondence, email: ajaya_nk@yahoo.com
}

\begin{abstract}
The distribution pattern and habitat preference of barking deer (Muntiacus muntjac Zimmermann) were analyzed during spring and rainy seasons of 2005 in Nagarjun Forest, Kathmandu. A total of 14 observations (seven males and seven females), 247 pellets and 118 footprints of barking deer were recorded in the spring and 14 observations (nine males and five females), 151 pellets and 140 footprints were recorded during the rainy season. The result showed uneven or clumped distribution patterns for deer in both spring $\left(\mathrm{S}^{2} \sqrt{\mathrm{X}}=\right.$ $\left.331.03>1 ; \chi^{2}=331.02, \mathrm{p}=0.01\right)$ and rainy season $\left(\mathrm{S}^{2} \sqrt{ } \mathrm{X}=233.48>1 ; \chi^{2}=233.48, \mathrm{p}=0.01\right)$. Among four types of habitats (Schima wallichii forest, mixed broadleaved forest, pine forest and dry oak forest), the mixed broadleaved forest was much preferred in spring $(\mathrm{RPI}=0.81)$ and pine forest during the rainy season $(\mathrm{RPI}=0.15)$.
\end{abstract}

Key words: Barking deer, Muntiacus muntjac, distribution, habitat preference, Nagarjun forest, Nepal

The barking deer (Muntiacus muntjac Zimmermann, Cervidae, Artiodactyla), also called muntjac, is a small, solitary ruminant, living in dense tropical and subtropical forests of Asia (Oli and Jacobson 1995, Shrestha 1997). Muntiacus spp. have a broad geographic range and are found in Indo-Malayan countries, China, Taiwan, Japan, Sri Lanka, north India and Nepal (Prater 1980). In Nepal, distribution, habitat use and preferences of the barking deer have been analyzed by many researchers (e.g. Tamang 1982, Heggdal 1999, Kuikel 2003, Thapa 2003, Pokharel 2005). Tamang (1982) reported that barking deer prefer Sal (Shorea robusta) and riverine forests, and are often seen on meadows in Chitwan. In Bardia, the barking deer prefer riverine forest followed by Sal forest with Mallotus as major associate (Heggdal 1999). Kuikel (2003) also observed the animals in the mixed forest, Sal forest and riverine forest. The distribution patterns of the species in various habitats have been documented by Thapa (2003) in Barandabhar Forest (Chitwan) and Pokhrel (2005) in Royal Suklaphanta Wildlife Reserve. They found that barking deer have a clumped distribution and show no significant difference in preference among the forested habitats.

Most studies on barking deer have focused on the lowlands of Nepal. Thus the information on barking deer distribution and habitat preference is inadequate for the mid-hills, which have experienced a higher rate of habitat loss and degradation. The present study has assessed the distribution, habitat use and diets of the barking deer in Nagarjun Forest. It is hoped that our findings will be useful for the management of barking deer in Nagarjun Forest as well as other parts of Nepal's middle hills.

\section{Materials and methods}

Study area Nagarjun forest $\left(27^{\circ} 43^{\prime} 37.13^{\prime \prime}\right.$ to $27^{\circ} 46^{\prime} 22.84^{\prime \prime} \mathrm{N}$; $85^{\circ} 13^{\prime} 52.97^{\prime \prime}$ to $85^{\circ} 18^{\prime} 14.38$ " E; 1220 to 2188 masl) lies on the northernmost border of Kathmandu Valley (Figure 1) and occupies an area of $16.45 \mathrm{~km}^{2}$. The study area is underlain largely by quartzite but also consists of limestone, siliceous limestone and calcisilicate rocks to some extent (Hagen 1959). Soil composition varies with forest type, ranging from dry hard, light brown to black soil with low to high humus content (Kanai et al. 1970). Mean monthly temperature in the study year ranged from 3.05 to $30.53^{\circ} \mathrm{C}$, relative humidity 54.7 to $94.2 \%$, rainfall 5.15 to $548.73 \mathrm{~mm}$. July, August and September are the most humid months, with highest precipitation in July and August. Forests in Nagarjun can be categorized into four types: Schima wallichii forest, pine forest, mixed broadleaved forest (Phoebe lanceolata, Machilus duthiei, Michelia kisopa as major species) and dry oak forest (Kanai and Shakya 1970). There are few small patches of grassy meadow (Nagarkoti 2006). The fauna includes bats, Presbytis entellus (common langur), Melursus ursinus (sloth bear), Martes flavigula (Himalayan yellow throated marten), Hieraaetus fasciatus (bonelli's eagle), Urocissa flavirostris (yellow-billed blue magpie), Urocissa erythrorhyncha (redbilled blue magpie) etc. (Malla 2000; Shrestha 2001).

Methods For ease of study, the entire forest was divided into four blocks, each $4.11 \mathrm{~km}^{2}$ (Figure 1). Habitat types were classified and mapped using a geographic information system (GIS). Line transects of $0.5-1.5 \mathrm{~km}$ length were laid out at 100 $\mathrm{m}$ intervals corresponding to the topographic contour lines

Himalayan Journal of Sciences 4(6): 70-74, 2007

Available online at www.himjsci.com

Copyright@2007 by Himalayan Association for the

Advancement of Science 


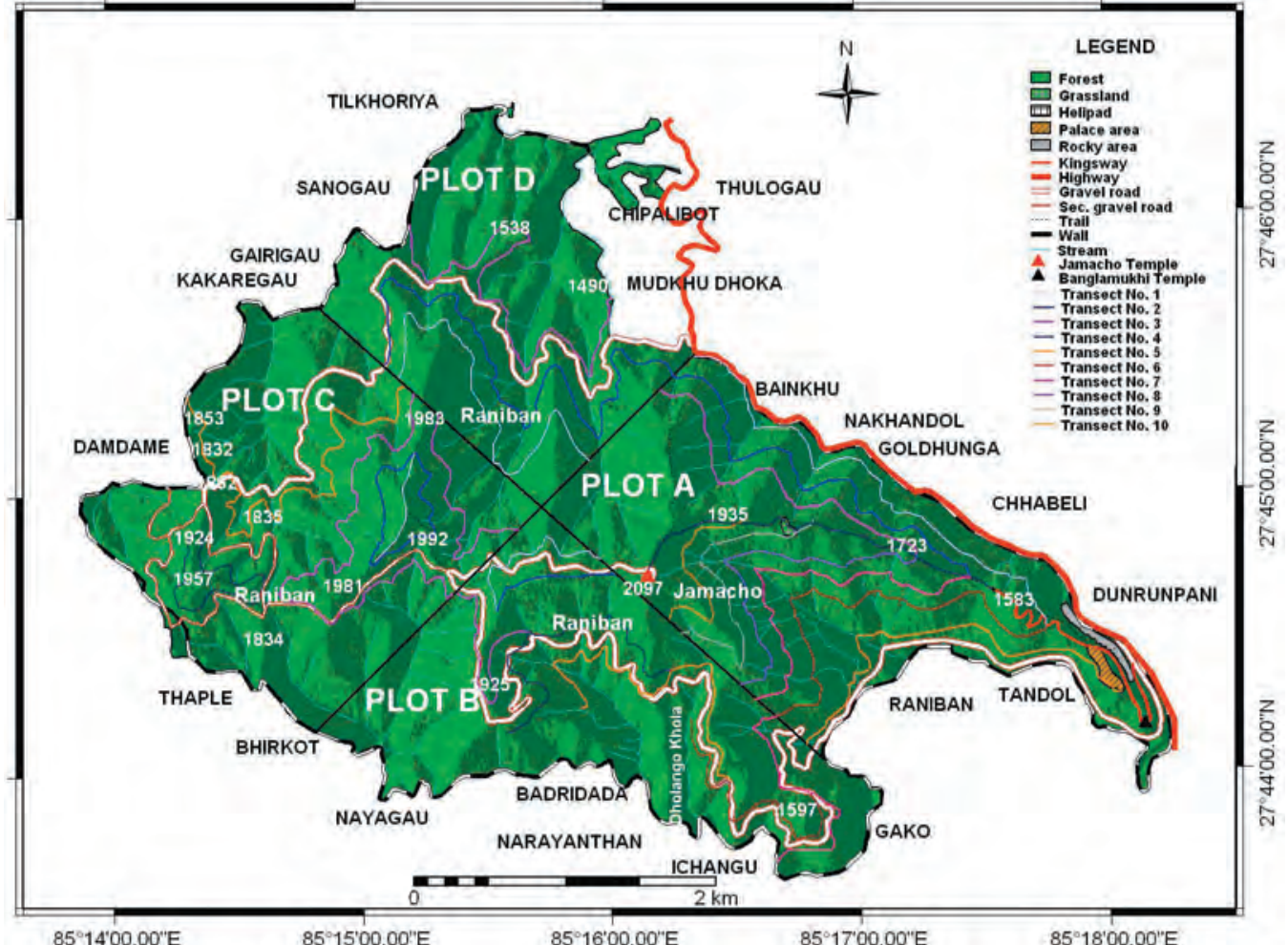

Figure 1. Study area with sampling plots and transects of maps. Plots A, B, C and D contained 10, 7, 5 and 3 transects respectively, as constrained by the topography. Data collection entailed a total of 144 hours of work over a period of sixteen days in each season (April-May and July-August). We recorded sightings of animals and other evidence such as footprints and pellets within five meters of the transect lines. At each sighting, we recorded the GPS coordinates, altitude and habitat type. We used observational data such as number of individuals, footprints and pellets recorded in each habitat type to determine the distribution pattern and habitat preference following the methods described by Jayson (1999).

We used a $\chi^{2}$ test to arrive at the distribution pattern and a relative preference index (RPI), one-way analysis of variance (ANOVA) to test differences in habitat use, and a t-test to quantify the difference between habitat use in the spring and rainy season. The deer's distribution pattern was calculated by variance-to-mean ratio (Odum 1971). A chi-square goodness-of-fit test was carried out to determine whether barking deer were distributed according to the availability of habitat types. According to Stinnett and Klebenow (1986),

We used area estimates of vegetation types obtained from topographic maps in order to calculate percentage availability of habitats.

\section{Results}

Forest cover Among the four types of forests recognized in Nagarjun hill, the Schima wallichii, forest constituted nearly $2 / 3$ rd of the total forest cover. In present study, we updated information on the boundaries of the various forest types; GIS analysis showed that coverage of Schima wallichii forest, mixed broadleaved forest, pine forest and dry oak forest in Nagarjun hill was $61.29 \%, 27.91 \%, 9.08 \%$ and $1.72 \%$, respectively.

Distribution During the spring we recorded 14 individuals (7 bucks and 7 does), 247 pellet groups and 118 footprints of barking deer; during the rainy season we observed 14 individuals ( 9 males and 5 females), 151 pellet groups and 140 footprints. In the spring of 2005, we found evidence of deer presence most frequently in mixed broadleaved forest (three males, two females, 121 pellets and 65 footprints); no such evidence was recorded in the dry oak forest. On the other hand, during the 2005 rainy season, the highest incidence of evidence was observed in Schima wallichii forest (nine males, five females, 151 pellets and 140 footprints) whereas only one footprint was recorded in dry oak forest. In the Nagarjun forest, barking deer were encountered in almost all areas. However, we found a clumped distribution pattern both during spring $\left(\mathrm{S}^{2} \sqrt{\mathrm{X}}=331.03>1\right)\left(\chi^{2}=331.03, \mathrm{p}=0.01\right)$ (Figure 2) and rainy seasons $\left(\mathrm{S}^{2} \sqrt{\mathrm{X}}=233.48>1\right.$; and $\chi^{2}=$ 233.48, $\mathrm{p}=0.01$ ) (Figure 3).

Habitat use and preference The mixed broad leaved forest was much preferred $(\mathrm{RPI}=0.81)$ in spring season while Schima wallichii forest (RPI $=-0.25)$ and pine forest $(\mathrm{RPI}=-0.62)$ were not preferred during this season. Dry oak forest was completely avoided (RPI $=-1$ ) during spring season. During rainy season the deer preferred pine forest $(\mathrm{RPI}=0.15)$ and mixed broad leaved forest $(\mathrm{RPI}=0.14)$ while Schima wallichii forest $(\mathrm{RPI}=-0.06)$ and dry Oak forest $(\mathrm{RPI}=-0.81)$ were not preferred (Figure 4). However, no significant difference was 


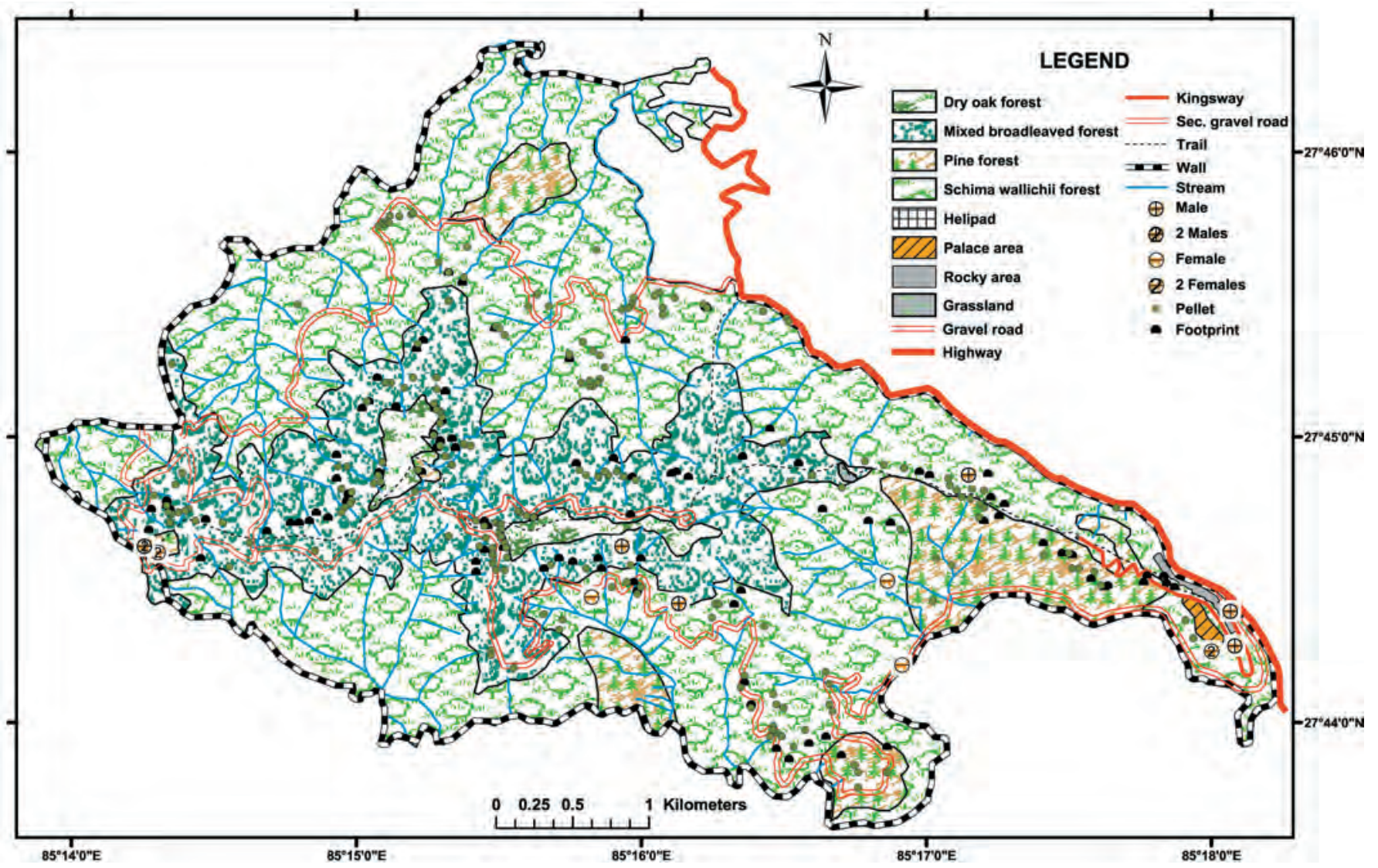

Figure 2. Distribution of barking deer in Nagarjun forest for spring season (2005)

found in using different habitat types by the deer ( $p>0.05)$. Similarly, the t-test also showed no significant difference in habitat use between spring and rainy seasons $(\mathrm{p}>0.05)$.

\section{Discussion}

The distribution of barking deer in the Nagarjun forest showed a clumped pattern which is presumably explained by the fact that in natural habitats such resources as food, water, and cover are not distributed uniformly. Barking deer exhibit seasonal differences in habitat preferences. The feeding habits of barking deer correspond to those of small African forest ruminants that Hofmann and Stewart (1972) characterize as 'selectors of juicy concentrated herbage'. Such food is relatively abundant in shrub habitats (Song and Li 1994). Dense canopy cover is another important factor in barking deer habitat selection (Teng et al. 2004). Preference for a high percent of canopy cover could be an anti-predatory strategy: in a forest or woodland, dense cover can minimize visual detection (Geist 1974). In the Royal Bardia National Park, Heggdal (1999) found that barking deer favored riverine forest for foraging and night-time habitat.

In the Nagarjun forest, coverage of shrub and surface layers was relatively dense in mixed broadleaved forest, as compared to that of other forest types (Kanai and Shakya 1970), causing concentration of deer in this habitat. Because barking deer usually drink water at least once a day, most often in the morning or midday, they like to remain close to a water source (Rafinesque 1968, Yonzon 1978). In the Nagarjun forest water sources are mainly available in the mixed broadleaved forest. Thus, the preference of barking deer for mixed-broad leaved forest in spring season is most

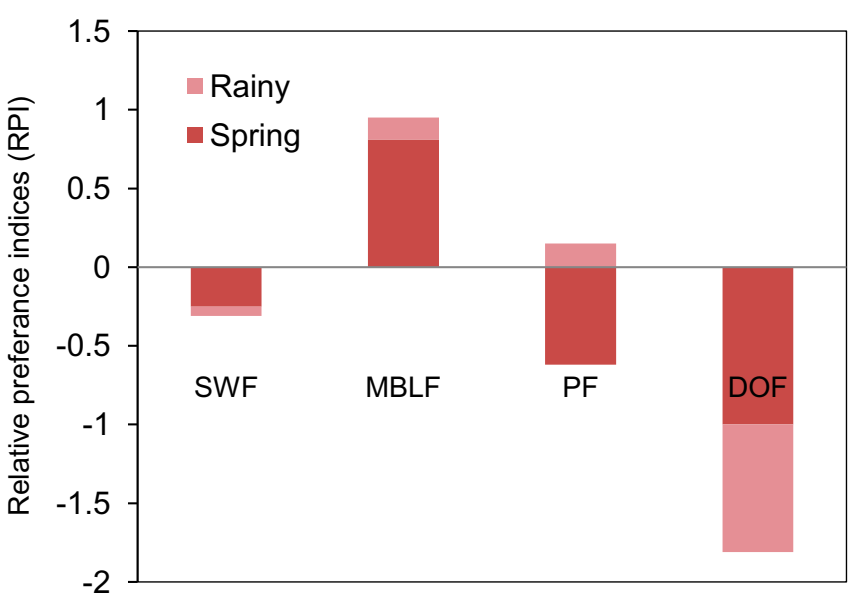

Figure 4. Relative preference indices (RPI) for habitat types during spring and rainy season, 2005. (SWF= Schima wallichii forest, $\mathrm{MBLF}=$ mixed broadleaved forest, $\mathrm{PF}=\mathrm{Pine}$ forest, and $\mathrm{DOF}=$ dry oak forest) 


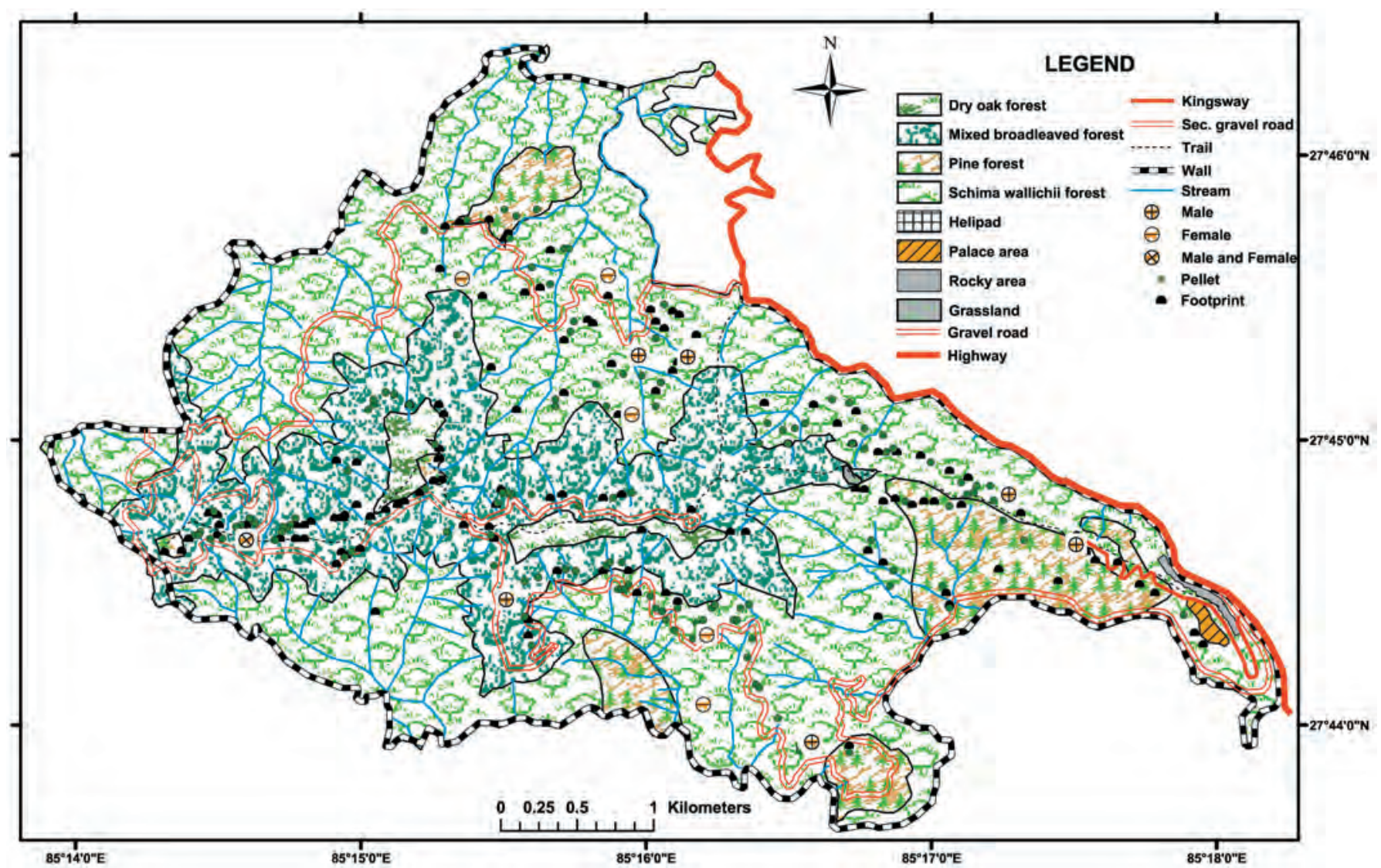

Figure 3. Distribution of barking deer in Nagarjun forest for rainy season (2005)

likely due to the availability of food, shelter and water sources. The slightly higher preference for pine forest as opposed to mixed-broadleaved forest $(\mathrm{RPI}=0.14$ ) during the spring may be explained by an inclination to avoid wet and muddy areas during the rainy season as mixed-broad leaved forest is wet and muddy at that time of the year. Wet and muddy areas are uncomfortable, dangerous and difficult to negotiate, and suboptimal sites for foraging and resting. The pine forest is relatively preferable and also drier in the rainy season than other habitat types in study area. In Royal Chitwan National Park the movement of barking deer in dry places increased during the monsoon season but remained less frequent than that of Chitals (Yonzon 1978). The presence of a substantial shrub layer (mostly fruit yielding Berberis asiatica) and surface layer (containing most preferred food Imperata cylindrica and Pogonatherum paniceum) significantly contribute to the habitat value of pine forest.

In conclusion, barking deer are unevenly distributed in Nagarjun forest. A clumped distribution pattern is found in both spring and rainy seasons. Although the deer is a generalist in habitat use, most individuals apparently prefer mixed broadleaved forest (in the spring) and pine forest (during the rain season) over other forest types.

\section{Acknowledgements}

We thank KK Shrestha and V Adhikari (Central Department of Botany, Tribhuvan University) for helping in plant identification.

\section{References}

Geist V. 1974. On the relationship of social evolution and ecology in ungulates. American Zoologist 14: 205-220

Hagen T. 1959. Geological map of Nepal (1951-1959) [Poster]. Kathmandu: Central Department of Geology, Tribhuvan University

Heggdal PO. 1999. Spatial organization, habitat preferences and activity of barking deer during the dry season in Royal Bardia National Park [MSc thesis]. Norway: Agricultural University. iv $+59 p$

Hofmann RR and DRM Stewart. 1972. Grazer or browser: a classification based on the stomach structure and feeding habits of East African ruminants. Mammalia 36: 226-240

Jayson EA. 1999. Habitat preference of five herbivores in the Chimmony Wildlife Sanctuary. Indian Forester 123(10): 975-985

Kanai H and PR Shakya. 1973. Vegetation Survey of Nagarjun Forest. In: Flora of Nagarjun [Bulletin of the Department of Medicinal Plants, No. 4]. Kathmandu: His Majesty's Government of Nepal, Ministry of Forests, Department of Medicinal Plants. p iii-vi, $1-93$ and I-XIX

Kanai H, PR Shakya and TB Shrestha. 1970. Vegetation survey of Central Nepal. Available: http://www.um.u-tokyo.ac.jp/ via the Internet. Accessed May 26, 2005

Kuikel PR. 2003. Study of wild ungulates in Royal Bardia National Park extension area [M. Sc. Thesis]. Kathmandu: Central Department Zoology, Tribhuvan University. vii $+51 p$

Malla R. 2000. Diet analysis of Hipposiderous armiger and Rhinolophus pursillus (Microchiroptera) of Nagarjun cave [MSc thesis]. Kathmandu: Central Department of Zoology, Tribhuvan University. 73p

Nagarkoti A. 2006. Distribution pattern, habitat preference and food habits of barking deer (Muntiacus muntjac Zimmermann) 
in Nagarjun Royal forest [MSc thesis]. Kathmandu: Central Department of Zoology, Tribhuvan University. $x+72 p$.

Odum EP. 1971. Fundamentals of Ecology. Philadelphia: W.B Sanders Company. xiv $+557 p$

Oli MK and HA Jacobson. 1995. Vocalizations of barking deer (Muntiacus muntjac) in Nepal. Mammalia 59(2): 179-186

Pokhrel S. 2005. Distribution and abundance of wild ungulates in Royal Suklaphanta Wildlife Reserve [MSc thesis]. Kathmandu: Central Department of Zoology, Tribhuvan University. 52+vi p

Prater SH. 1980. The book of Indian Animal (III edition). Bombay: Bombay Natural History Society. xxiii $+324 \mathrm{p}$

Rafinesque 1968. Artiodactyla; Cervidae; Genus: Muntiacus. In: EP Walker, 1968, Mammals of the World (II edition). Baltimore: The Johns Hopkins Press. Vol-II, 1355 p

Shrestha TK. 1997. Mammals of Nepal (With reference to those of India, Bangladesh, Bhutan and Pakistan). Kathmandu: Bimala Shrestha. $247 \mathrm{p}$

Shrestha TK. 2001. Birds of Nepal: Field Ecology, Natural History and Conservation. Kathmandu: Bimala Shrestha. Vol II, xiv +562p
Song YL and SY Li. 1994. Habitat selection and utilization of Hainan Eld's Deer. In: Proceeding of the Sixth Anniversary of the Founding of China Zoological Society (ed. China Zoological Society). Beijing: Chinese Science and Technology Press. p 457-461

Stinnett D P and DA Klebenow. 1986. Habitat use of irrigated lands by California quail in Nevada. Journal of Wildlife Management 50: $365-372$

Tamang KM. 1982. The status of the tiger (Panthera tigris) and its impact on the principal prey population in the Royal Chitwan National Park, Nepal [PhD dissertation]. Michigan: Michigan State University. 123p

Teng L, Z Liu, YL Song and Z Zen. 2004. Forage and bed sites characteristics of Indian muntjac (Muntiacus muntjac) in Hainan Island, China. Ecological Research 19: 675-681

Thapa V. 2003. Habitat heterogeneity and distribution of some ungulate prey species in Barandabhar Forest, Chitwan, Nepal [MSc thesis]. Norway: Agriculture University. vii $+79 p$

Yonzon PB. 1978. Ecological studies on Muntiacus muntjac Zimmermann. Journal of Natural History Museum 2(2): 91-100 